\title{
Lusioersily
}

\section{Micro- and Nano-scale Tribo-Corrosion of Cast CoCrMo}

Sun, D., Wharton, JA., \& Wood, RJK. (2011). Micro- and Nano-scale Tribo-Corrosion of Cast CoCrMo. Tribology Letters, 41, 525-533.

Link to publication record in Ulster University Research Portal

\section{Published in:}

Tribology Letters

Publication Status:

Published (in print/issue): 06/02/2011

\section{Document Version}

Publisher's PDF, also known as Version of record

\section{General rights}

Copyright for the publications made accessible via Ulster University's Research Portal is retained by the author(s) and / or other copyright owners and it is a condition of accessing these publications that users recognise and abide by the legal requirements associated with these rights.

\section{Take down policy}

The Research Portal is Ulster University's institutional repository that provides access to Ulster's research outputs. Every effort has been made to ensure that content in the Research Portal does not infringe any person's rights, or applicable UK laws. If you discover content in the Research Portal that you believe breaches copyright or violates any law, please contact pure-support@ulster.ac.uk. 


\title{
Micro- and Nano-scale Tribo-Corrosion of Cast CoCrMo
}

\author{
D. Sun · J. A. Wharton · R. J. K. Wood
}

Received: 9 February 2010/Accepted: 24 January 2011/Published online: 6 February 2011

(C) Springer Science+Business Media, LLC 2011

\begin{abstract}
Previous studies have established that some of the wear damage seen on cast CoCrMo joint surface is caused by entrained third-body hard particles. In this study, wet-cell micro-indentation and nano-scratch tests have been carried out with the direct aim of simulating wear damage induced by single abrasive particles entrained between the surfaces of cast CoCrMo hip implants. In situ electrochemical current noise measurements were uniquely performed to detect and study the wear-induced corrosion as well as the repassivation kinetics under the micro-/nanoscale tribological process. A mathematical model has been explored for the CoCrMo repassivation kinetics after surface oxide film rupture. Greater insights into the nature of the CoCrMo micro-/nano-scale wear-corrosion mechanisms and deformation processes are determined, including the identification of slip band formation, matrix/carbide deformation, nanocrystalline structure formation and strain-induced phase transformation. The electrochemical current noise provides evidence of instantaneous transient corrosion activity at the wearing surface resulting from partial oxide rupturing and stripping, concurrent with the indent/scratch.
\end{abstract}

Keywords Biotribology $\cdot$ Wear mechanisms

D. Sun · J. A. Wharton · R. J. K. Wood

National Centre for Advanced Tribology at Southampton (nCATS), School of Engineering Sciences, University of Southampton, Highfield, Southampton SO17 1BJ, UK

D. Sun $(\bowtie)$

Nanotechnology and Integrated Bioengineering Centre (NIBEC), School of Engineering, University of Ulster at Jordanstown, Northern Ireland BT37 0QB, UK

e-mail: sun_dan@hotmail.com; d.sun@ulster.ac.uk

\section{Introduction}

Wear and corrosion of CoCrMo-based hip joints have received increasing attention in recent years. Both retrieved joint surfaces $[1,2]$ and laboratory simulator studies [3, 4] have revealed that two-body sliding wear and three-body abrasion are the predominant wear mechanisms for metalon-metal (MoM) implants, where sub-micron-sized hard particles such as fractured carbides, bone cement, bone and metal debris have been recognized as the agents inducing third-body abrasion [5-7]. Previously, microscale abrasioncorrosion of cast CoCrMo [8-12] has been studied by the present authors using a ball cratering rig incorporating a liquid tank, and the wear damage of CoCrMo surface under those test conditions was mainly caused by the entrainment of multiple abrasives. One question left unanswered, however, is the effect of single abrasive particle on tribocorrosion behaviour of CoCrMo. There is a lack of detailed understanding of the role of a single abrasive particle on the micro- and nano-scale tribo-corrosion of CoCrMo in the orthopaedic tribology literature. The present investigation therefore aims to gain an insight into the micro-/ nano-scale wear-corrosion behaviour of CoCrMo with the aid of wet-cell micro-indentation and nano-scratching techniques. It should be noted that the emphasis of this study is not to completely simulate the actual clinical wear, but to establish robust test protocols for mechanistically evaluating the wear characteristics of cast CoCrMo that may be related to clinical wear performance.

\section{Experimental}

Cast F-75 CoCrMo used in this study was supplied by Finsbury Orthopaedics and its details composition can be 


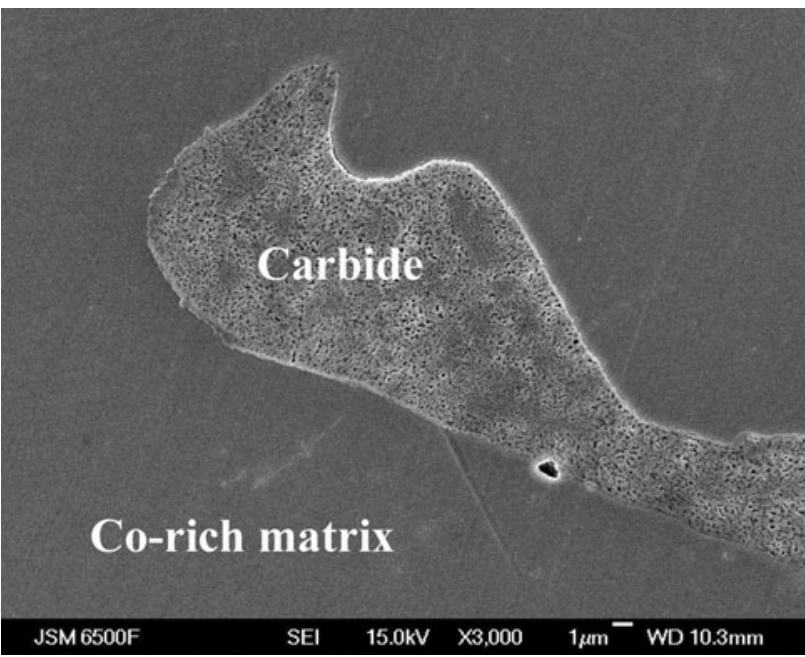

Fig. 1 SEM image of cast CoCrMo surface and microstructure

found elsewhere [10]. Figure 1 shows a typical SEM image of a cast CoCrMo surface, where carbide blocks stand proud of the surface and have a different microstructure from the Co-rich matrix. The carbides are about $200 \mathrm{~nm}$ higher than the surrounding Co-rich matrix and are typically $25 \mu \mathrm{m}$ in size. The average Vickers hardness value of the cast CoCrMo specimen was about $4 \mathrm{GPa}$ under $10 \mathrm{~kg}$ (98 N) weight.

The CoCrMo specimens $(20 \mathrm{~mm} \times 10 \mathrm{~mm} \times 3 \mathrm{~mm})$ were wet ground using 120 and 4000 grit $\mathrm{SiC}$ paper. For electrochemical current noise measurements, the specimens were polished using 6 and $1 \mu \mathrm{m}$ diamond pastes (Buehler, USA) on the respective polishing clothes (Struers Ltd, UK), and the final surface roughness $\left(R_{\mathrm{a}}\right)$ of the specimen was about $0.01 \mu \mathrm{m}$. The test solutions used were $0.9 \% \mathrm{NaCl}$ and/or $25 \%$ bovine serum (BS) from Harlan ${ }^{\circledR}$ SERA-LAB, both buffered to $\mathrm{pH} 7.4$ and all testing was conducted at $37{ }^{\circ} \mathrm{C}$. Detailed microstructural analysis involving SEM and Electron Backscattered Diffraction (EBSD) also required the elimination of the original polishing mark artefacts resulting from the metallographic preparation. Therefore specimens were electro-polished after metallurgical preparation using a $7-\mathrm{vol} . \%$ perchloric acid/93 vol.\% acetic acid solution at $10{ }^{\circ} \mathrm{C}$ and an applied voltage of $30 \mathrm{~V}$ for $60 \mathrm{~s}$.

A Vickers micro-hardness indenter was used, which was fitted with a wet-cell in order to simulate the immersed condition as in the in vivo environment. A three-electrode electrochemical cell was also fitted into the wet cell to allow in situ electrochemical current noise measurements, see Fig. 2.

During the tests, the single micro-indent test drives the indenter downward at a load of $9.8 \mathrm{~N}$ and drives upward after a dwell of $5 \mathrm{~s}$. Single or multiple indentations (the procedure was repeated five times with an intermission of $10 \mathrm{~s}$ at the same location) have been performed at $37{ }^{\circ} \mathrm{C}$ to investigate the CoCrMo mechanical/electrochemical behaviour under single and multiple loading/unloading cycles.

The wet-cell nano-scratch test was carried out by the nanoindenter (NanoTest platform, MicroMaterials Ltd, UK), see Fig. 3. A three-electrode electrochemical cell has been incorporated in the wet-cell. A conical diamond indenter $(10 \mu \mathrm{m}$ tip radius $)$ was used for the scratching tests.

For the wet-cell nano-scratching test, the load was ramped up abruptly to $200 \mathrm{mN}$. A $1000-\mu \mathrm{m}$ scratch was made at a scratching speed of $100 \mu \mathrm{m} \mathrm{s}^{-1}$ (maximum speed allowable for the instrument). Single or repeated scratches (5 or 20 passes made at the same location) were carried out in order to investigate the effect of single or multiple scratch cycles on the local plastic deformation and material electrochemical response. The system was set up

Fig. 2 Set-up for wet-cell

micro-indentation

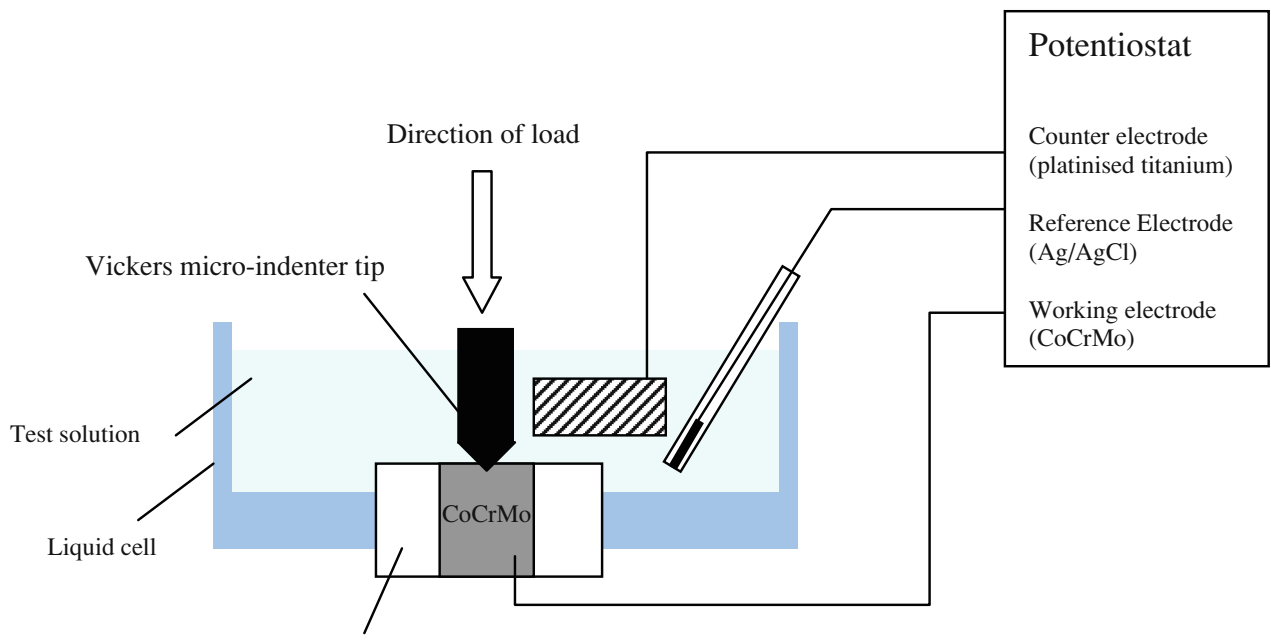

Polymer moun 


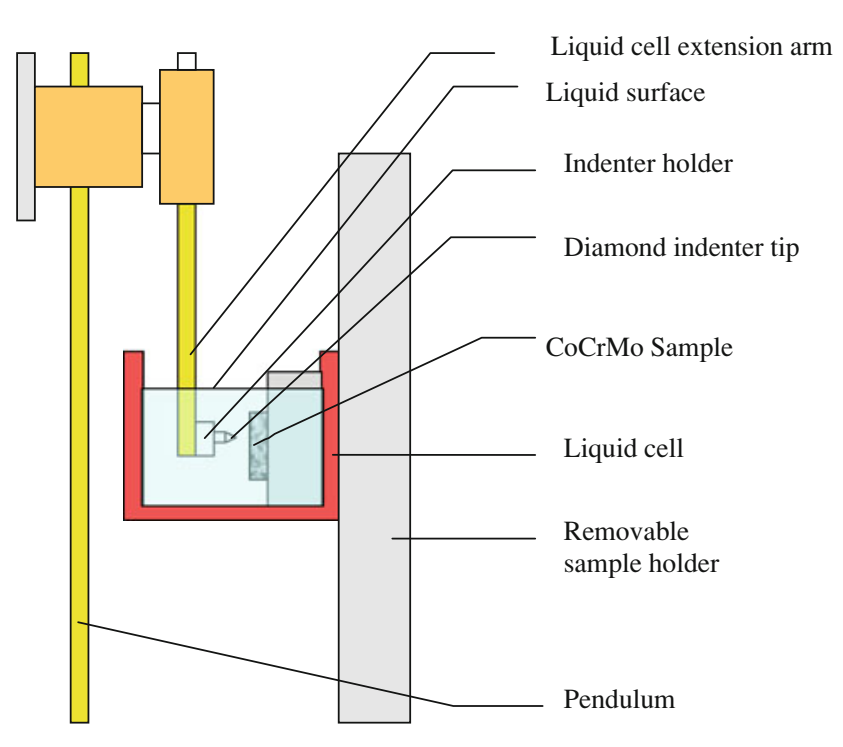

Fig. 3 Set-up for wet-cell nano-scratching

in the way that after each pass the indenter was unloaded and returned to the original starting location.

All test specimens for in situ electrochemical current noise measurements were immersed in the test solution for 30 min prior to tests. Electrochemical current noise data were collected using a PC4/750 Gamry potentiostat using a sampling frequency of $2 \mathrm{~Hz}$ and analysed with ESA 400 software. The electrochemical current noise was measured under potentiostatic mode using an applied potential equal to the open-circuit potential of CoCrMo measured at $30 \mathrm{~min}$ immersion-OCP30 $0_{\min }$ (approx. $-130 \mathrm{mV}$ vs. $\mathrm{Ag}$ / $\mathrm{AgCl}$ reference electrode).

\section{Results and Discussions}

\subsection{Micro-Indentation and Associated Electrochemical Current Noise}

Single and multiple $(\times 5)$ indents were performed in $0.9 \%$ $\mathrm{NaCl}$ and/or $25 \% \mathrm{BS}$ in a fully immersed condition. Figure 4a shows the loading and unloading current transient for a single indentation test made in $0.9 \% \mathrm{NaCl}$ (applied load of $9.8 \mathrm{~N}$ ). At the initial period of the current measurement (the first $10 \mathrm{~s}$ ), the current rapidly reaches a limited steady-state (approx. $-1 \mathrm{nA}$ ) immediately after the closed-circuit was established within the electrochemical cell. This response is due the $-130 \mathrm{mV}$ applied potential under potentiostatic mode perturbing the surface-reacting to the sudden change for OCP to potentiostatic control. Overall, the background current is low (approx. $-1 \mathrm{nA}$ ), this is a response of the true sample potential being similar but not identical to $\mathrm{OCP} 30_{\mathrm{min}}$. When the indenter comes into contact with the specimen surface and is driven
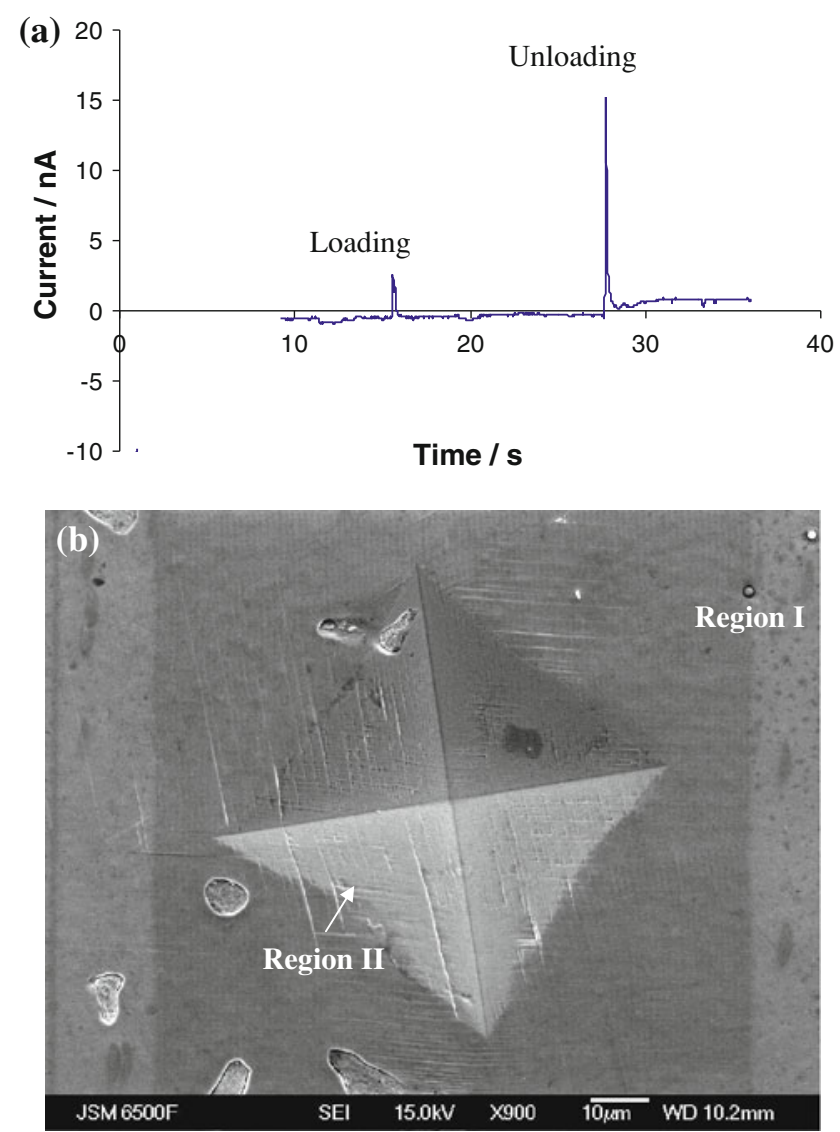

Fig. 4 a In situ electrochemical current noise of Vickers microindentation made in $0.9 \% \mathrm{NaCl}$ under $9.8 \mathrm{~N}$ applied load and b SEM image of a microindent

downwards, a small anodic peak $(<5 \mathrm{nA})$ is detected which corresponds to the passive film rupturing. The current returns to the pre-indentation level while the indenter remained in the loaded position. During unloading (indenter moves away from the deformed surface), an intense current peak occurs (approx. $20 \mathrm{nA}$ ). The larger current peak which was produced during unloading is likely to be caused by exposure of the deformed metal/ oxide surface (which is previously masked by the indenter during loading) to the electrolyte solution. The anodic current flow during this process is partly due to the metal dissolution (metal-ion release) and partly contributed to the passive film formation. Figure $4 \mathrm{~b}$ shows the SEM image of a typical microindent where it can be seen that slip lines emerged as a result of the local plastic deformation. The interactions of dislocations and the resulted high-defect density could lead to a greater dissolution activity of the alloy.

Figure 5 shows Kikuchi patterns [13] obtained from EBSD map which correlates to the indented area shown in Fig. 4b. According to EBSD phase mapping, a FCC structure is the predominant crystal structure for the 


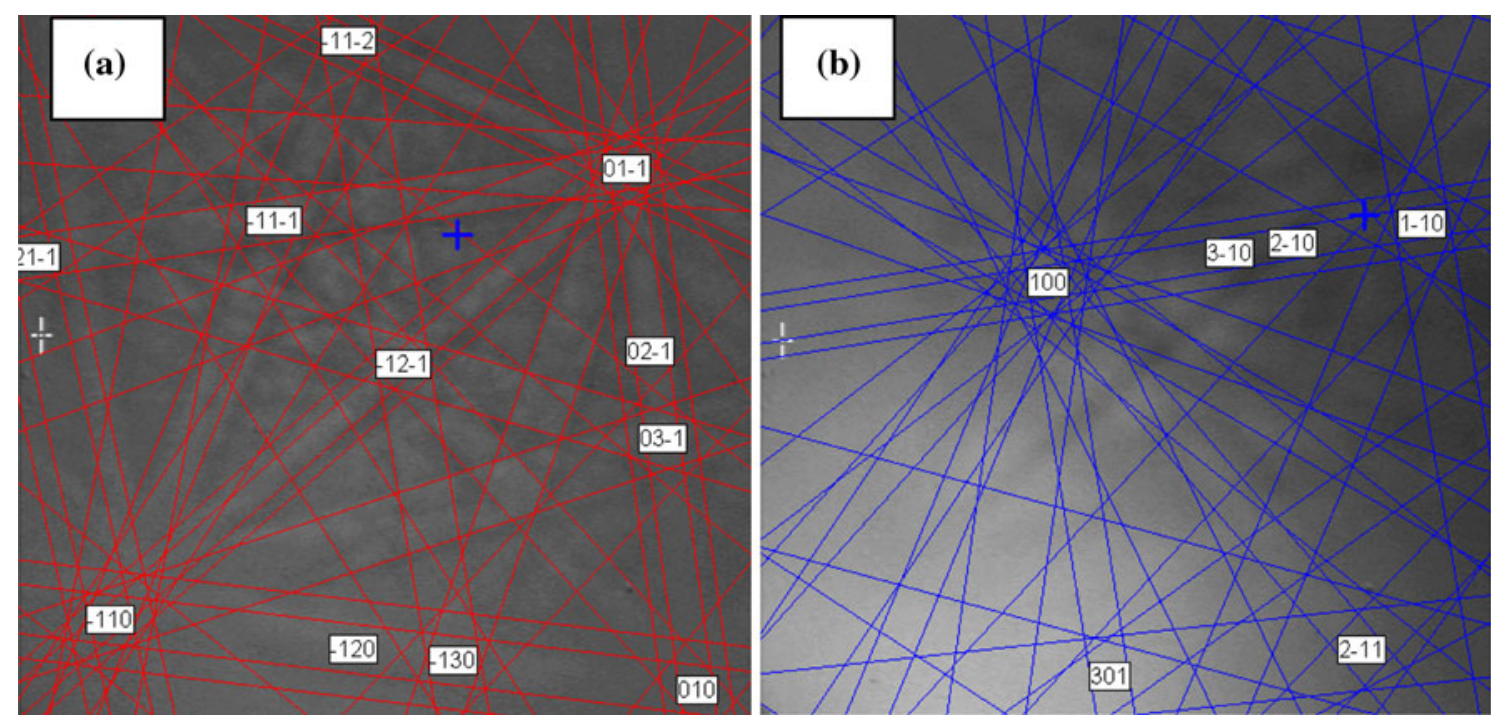

Fig. 5 Kikuchi pattern obtained for microindent shown in Fig. 4b. a Undamaged surface (Region I) and b deformed surface (Region II)

Fig. 6 Slip line formation results in corrosion cell which induces accelerated corrosion and metal-ion release [16]

\begin{abstract}
Approx. 1 nA oxide film
\end{abstract}
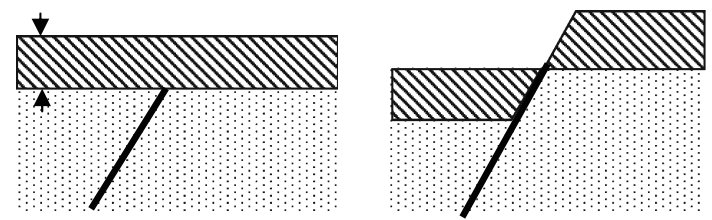

Rupture of oxide film during tribological processes

\section{Micro-/nano-galvanic corrosion cell may form}

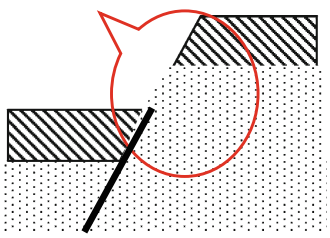

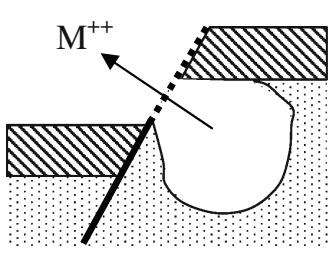

Accelerated corrosion and metal-ion release undeformed material (Region I), which is featured by the pattern centred at $[\overline{1} 10]$. Although there maybe traces of martensite present in the 'as cast' samples due to the casting process, such martensite has not been indentified from the current EBSD analysis on the polished/etched surface. Hexagonal Close Packed (HCP) phases (possibly as a result of strain-induced phase transformation, SIT) were only found at the points where severe deformation has taken place (e.g. Region II). A martensitic transformation takes place, resulting in a HCP structure featured by the [100] direction in the Kikuchi pattern. This also gives rise to the orientation relationship: $\{111\}_{\mathrm{FCC}} / /(0001)_{\mathrm{HCP}}$ and $\langle 2 \overline{2} 0\rangle_{\mathrm{FCC}} / /\langle\overline{2} 110\rangle_{\mathrm{HCP}}$. This conforms with the crystallographic relationship between FCC and HCP as seen for pure cobalt [14].

For a FCC structure, the stacking fault is essentially a very thin layer of $\mathrm{HCP}$, so that such a fault may be an effective coherent nucleus in transformations between the two phases. One possibility is that at a sufficiently high driving force, the effective fault energy becomes negative so that spontaneous dissociation of existing dislocations into very wide faults takes places. A group of dislocations could then lead to a multilayer set of faults which, if suitably spaced, constitute a region of the new phase [15]. In addition, it is worth mentioning that the HCP phase has not been found within the whole deformed region of the indent (apart from region II), this might be due to the nonuniform force experienced by the CoCrMo under the indent or due to the inhomogeneous nature of the crystal structure.

Figure 6 illustrates the depassivation and partial surface oxide film rupture caused by the slip line formation. The oxide film formed on the CoCrMo surface ruptures under the shear stress/plastic deformation. As the rupture of passive film also occurs outside the indent via slip line 
formation (see Fig. 4b), the total affected area due to the tribological process is greater than the actual indent area. The plastic deformation process may be accompanied by local SIT [15], at the same time the sub-surface bare alloy is exposed to the external corrosive environment. The exposed bare alloy is of different corrosion potential with the oxide film and therefore a local micro-galvanic cell may form. This may subsequently lead to accelerated metal dissolution and metal-ion release. The predominant corrosion reactions during the tribo-corrosion processes are likely to be:

Anodic:

$\mathrm{Co} \rightarrow \mathrm{Co}^{2+}+2 \mathrm{e}^{-}$

$\mathrm{Cr} \rightarrow \mathrm{Cr}^{3+}+3 \mathrm{e}^{-}$

Cathodic:

$\mathrm{O}_{2}+2 \mathrm{H}_{2} \mathrm{O}+4 \mathrm{e}^{-} \rightarrow 4 \mathrm{OH}^{-}$

Figure 7 shows the current noise collected during the multiple indentation process in $0.9 \% \mathrm{NaCl}$ solution. The current peak and charge released are both significantly greater for the first indentation cycle as compared with those at the second and the subsequent indentations. This could be due to the plastic deformation that takes place during the first indentation, while elastic deformation is predominant for the second and subsequent indentations [17]. The indent size (approx. $100 \mu \mathrm{m}$ diagonally) and profile of a multiple indent appear to be similar to those seen for single indentation.

Figure 8 shows the multiple indentations performed in $25 \%$ BS under the same indentation conditions as for the $0.9 \% \mathrm{NaCl}$ tests, which gave rise to a similar indent profile and current response as seen in Fig. 7. The current peak during unloading is always larger than that during the respective loading process. The current peak and the charge released are approximately constant for the second and subsequent loading/unloading cycles, since after the first

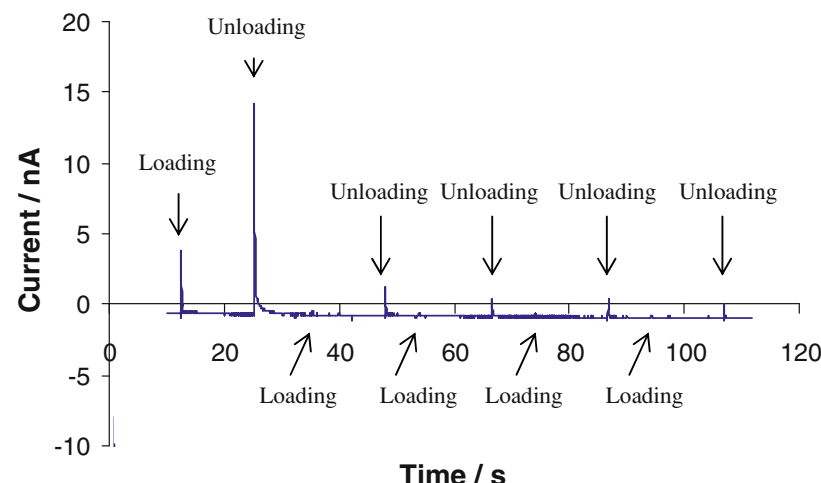

Fig. 7 In situ electrochemical current noise of multiple $(\times 5)$ Vickers micro-indentation made in $0.9 \% \mathrm{NaCl}$ under $9.8 \mathrm{~N}$ applied load

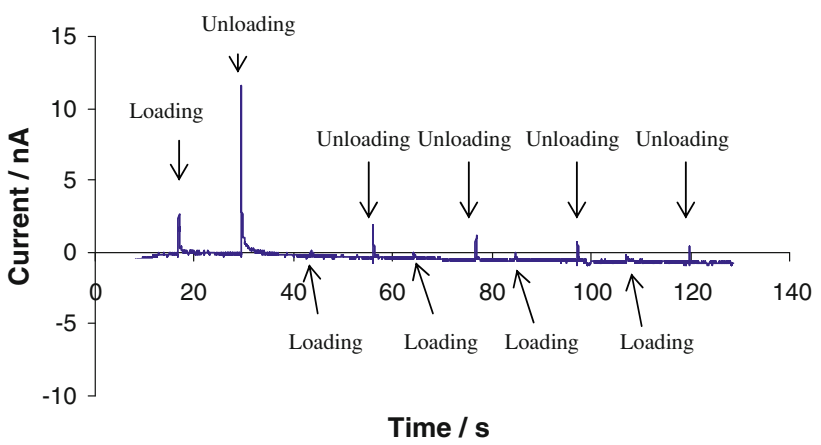

Fig. 8 In situ electrochemical current noise of multiple $(\times 5)$ Vickers micro-indentation made in $25 \%$ BS under $9.8 \mathrm{~N}$ applied load

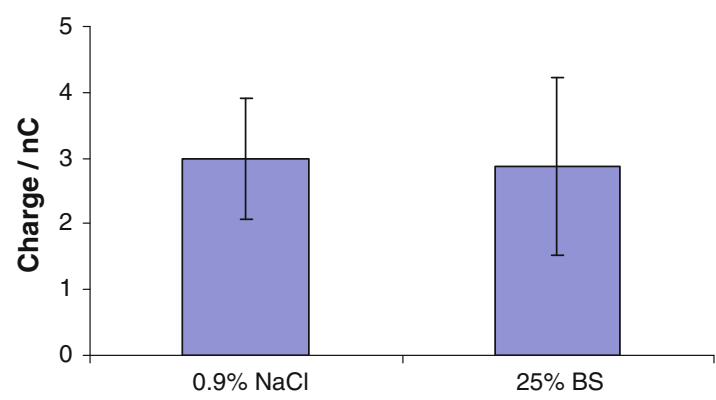

Fig. 9 Charge generated in $0.9 \% \mathrm{NaCl}$ and $25 \%$ BS test solutions during the first micro-indentation unloading, error bars based on three repeated tests

loading/unloading cycle, further plastic deformation is limited, thus the repassivation film is only partially damaged and recovers at much smaller current levels under an elastic deformation regime.

The higher peak current resulting from the unloading process of the first indentation cycle corresponds to the major current flow event throughout the multiple cycle test. The charge generated during the unloading process was determined using Faraday's law and shown at similar levels for both the $0.9 \% \mathrm{NaCl}$ and $25 \%$ BS solutions, see Fig. 9. According to a previous study [12], the surface oxide film thickness of cast CoCrMo is about $0.88 \mathrm{~nm}$. Assuming during repassivation, the anodic current flow is for oxide film repair only (reformation of $\mathrm{Cr}_{2} \mathrm{O}_{3}$ ), the percent area of film being repaired (repair \%) within the deformed region during the first loading/unloading cycle is about $6 \%$ of the total deformed area. The detailed calculation can be found in the Appendix. Repair \% would be lower if the metal dissolution is taken into account for the anodic current generated; however, the extent of metal ion dissolution is difficult to be quantified in this study. It can be suggested that the CoCrMo is only subject to partial surface oxide damage under the indented area during the indentation process. 


\subsection{Nano-scratching}

Figure 10a shows a typical example of single/multiple scratches made on CoCrMo surfaces, and Fig. 10b shows a close-up image of a multiple scratch (5 passes). The dominant features of the microstructures were deformation of cobalt matrix and carbide, as well as the development of numerous intersecting slip lines, as have been seen from Fig. 4. These features were a result of the plastic deformation of the alloy. According to Shetty et al. [15], the coarse slip bands are evidence of the planar slip character which should be expected in a FCC Co-rich matrix of low stacking fault energy. In [15], slip band cracking has also been observed in the scratch groove which was accompanied by SIT (FCC to HCP). According to the EBSD
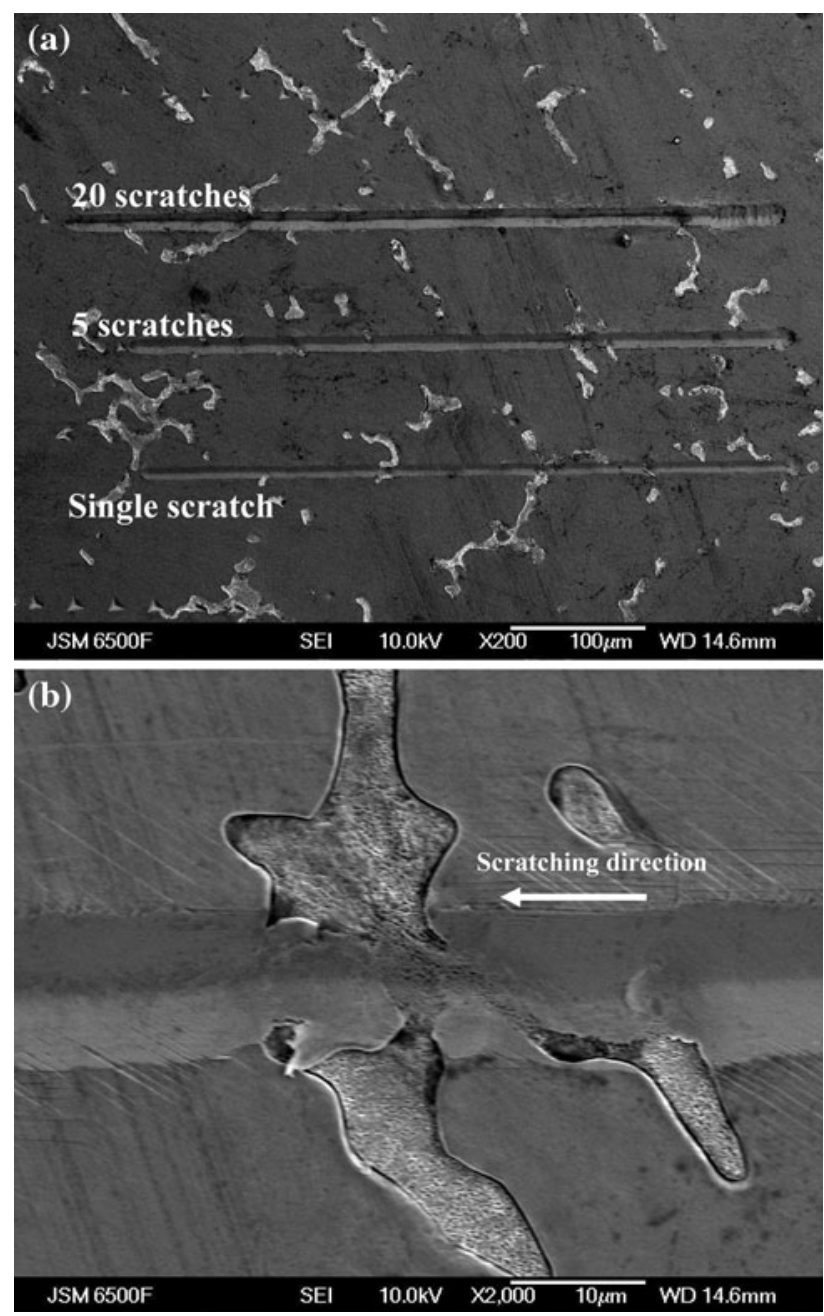

Fig. 10 a Single and multiple scratches on CoCrMo and b highmagnification image of a 5-pass scratch. Test conditions: load $=200 \mathrm{mN}, \quad$ scratching $\quad$ speed $=100 \mu \mathrm{m} \mathrm{s}^{-1}, \quad$ scratch distance $=1000 \mu \mathrm{m}$ analysis of the scratches, the HCP phase has also been observed at certain regions with severe plastic deformation.

In order to understand the effects of nano-scratching on the corrosion behaviour of the CoCrMo alloy, scratchinduced corrosion current was measured in situ during the single scratch test in $0.9 \% \mathrm{NaCl}$ and $25 \% \mathrm{BS}$ test solutions, respectively. Figure 11 shows the typical examples for current noise caused by scratching in both test solutions. The baseline current has been off-set for clarity.

It can be seen from Fig. 11 that there is an increase in the current level as the scratch starts corresponding to the rupture of the surface oxide film (depassivation) due to local plastic deformation. The gradual increase of current at the onset of the scratch may be due to the loading process of the diamond probe which takes about $1 \mathrm{~s}$. The current level during scratching is generally $1-2 \mathrm{nA}$ higher than the baseline current, although the current pattern (fluctuation) varies in different tests. The scratch current variation can be attributed to the fact that each scratch was made at a different location on the CoCrMo specimen surface, and the absolute current response will be sensitive to the surface
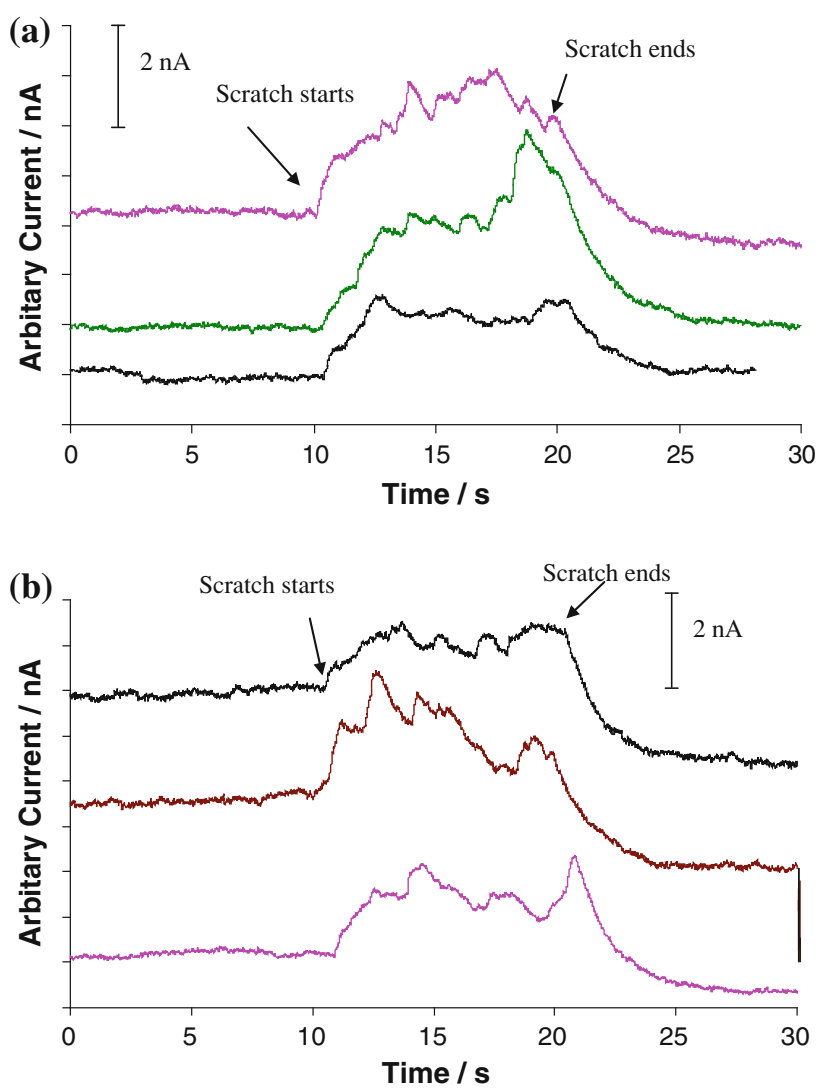

Fig. 11 Current profiles induced by three single scratch tests: a $0.9 \%$ $\mathrm{NaCl}$ and $\mathbf{b} 25 \% \mathrm{BS}$, at an applied potential of $-130 \mathrm{mV}$ versus $\mathrm{Ag} /$ $\mathrm{AgCl}$. Test conditions: load $=200 \mathrm{mN}$, scratching speed $=100 \mu \mathrm{m} \mathrm{s}^{-1}$, scratch distance $=1000 \mu \mathrm{m}$ 


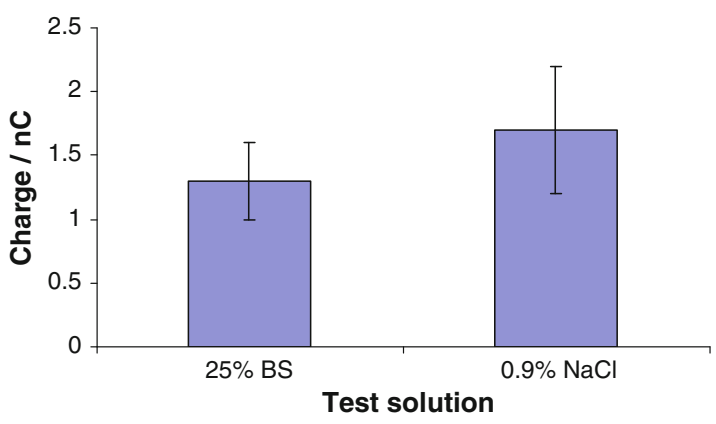

Fig. 12 Charge generated in $0.9 \% \mathrm{NaCl}$ and $25 \%$ BS test solutions during nano-scratch testing, error bars were obtained based on three repeated tests

morphology (crystal orientation, grain boundaries, and carbide distribution) and the in situ microstructural change (slip line formation and SIT). As the scratch is completed, the current gradually recovers to its pre-scratching level indicating repassivation is taking place. The scratching speed employed in this study was $100 \mu \mathrm{m} \mathrm{s}^{-1}$ (which is the maximum speed allowable by the instrument). Such low scratching speed allows part of the damaged surface to repassivate as the diamond probe moves forward, leaving only a small portion of the bare surface (which is immediately behind the scratching probe) exposed during the scratching. It is likely that a higher scratching speed will result in higher scratch-induced current.

As shown in Fig. 12, the total charge transferred during the scratching process (up to the point where indenter stopped sliding, not including the repassivation period) is about $1.3 \times 10^{-9}$ and $1.7 \times 10^{-9} \mathrm{C}$ for $25 \% \mathrm{BS}$ and $0.9 \%$ $\mathrm{NaCl}$, respectively. Assuming the current flow due to metal-ion release is negligible and electron transfer was only associated with the oxide reformation, the total repaired oxide film area is only about 15 and $20 \%$ of the total scratch area for scratches made in $25 \% \mathrm{BS}$ and $0.9 \%$ $\mathrm{NaCl}$, respectively. Although some literature suggests proteinaceous material could act as cathodic inhibitor and thereby hinder charge transfer $[10,18]$, the presence of an adsorbed protein could also form an organometallic tribofilm which will protect the surface from mechanical damage and ion release [19], the effect of the test solutions on the level charge transfer cannot be clearly discriminated due to the relatively high $(20-30 \%)$ variation in data.

Similar to the result seen for the microindentation, this may suggest that the CoCrMo is only subject to partial surface damage during the scratching. Under plastic deformation, the local slip line formation causes the rupture of surface oxide film, which may in turn become the sites for repassivation and the associated current flow. Conversely, the majority of the oxide film (area in between slip lines and outside the scratch area) may remain intact.
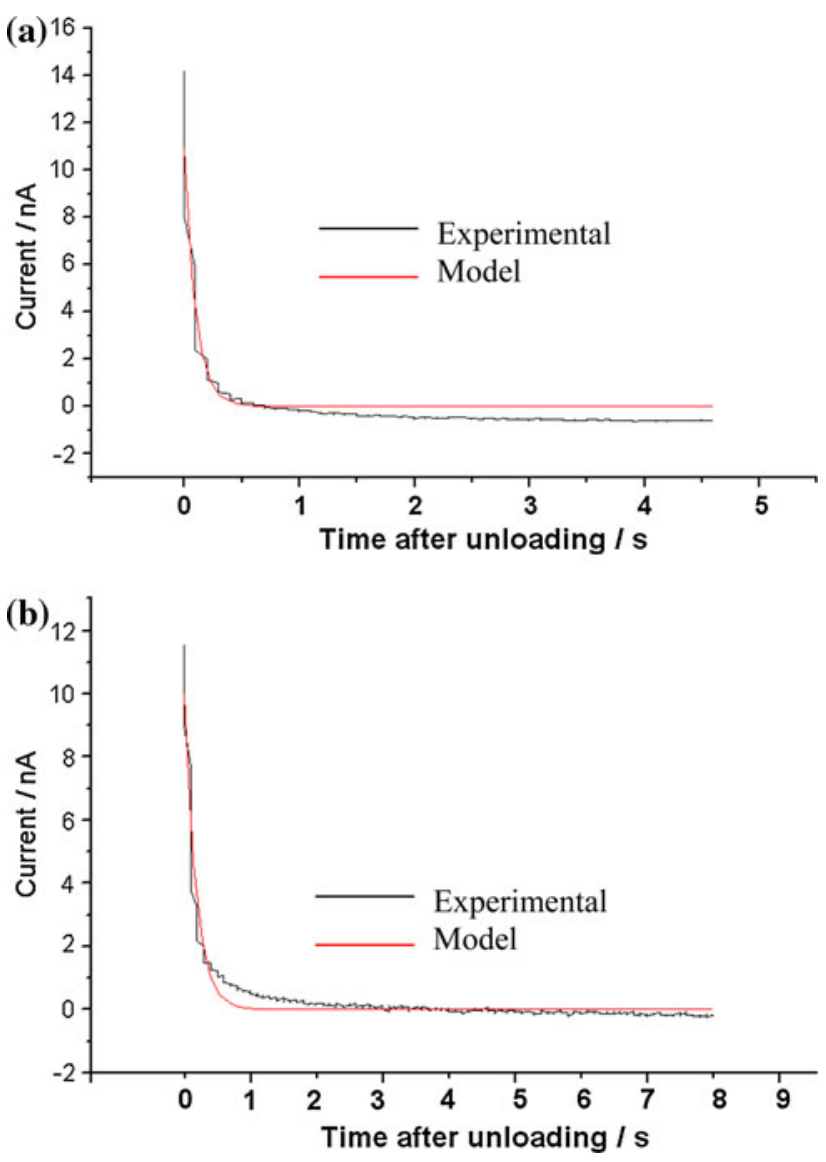

Fig. 13 Curve fitting for the repassivation process after wet-cell microindentaion (1st unloading): a $0.9 \% \mathrm{NaCl}$ and b $25 \% \mathrm{BS}$

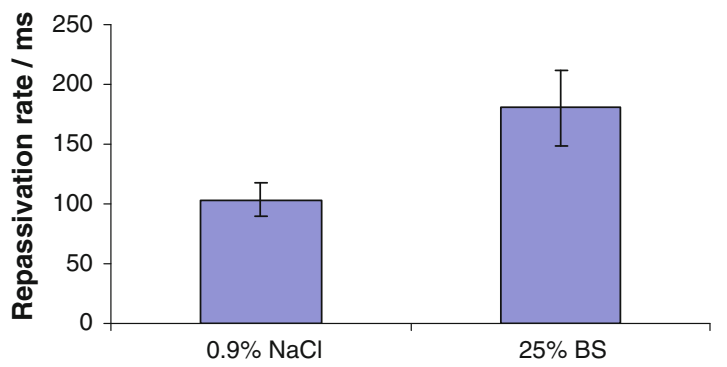

Fig. 14 Repassivation time for $0.9 \% \mathrm{NaCl}$ and $25 \% \mathrm{BS}$ test solutions resulted from the first unloaded microindentaion

\subsection{CoCrMo Repassivation Kinetics}

The electrochemical process involved in microindentaion has been discussed in Sect. 3.1, the repassivation process immediately after the intense current peak of first loading/ unloading cycle can be closely described by a first-order exponential decay function (Eq. 4) for tests done in $0.9 \%$ $\mathrm{NaCl}$ and 25\% BS solution, Fig. 13. The repassivation time constant, $\tau$, can be extracted from the fitted curve, and the 
value has been found to be greater for the $25 \% \mathrm{BS}$ test (about $180 \mathrm{~ms}$ ) than that for the $0.9 \% \mathrm{NaCl}$ test $(100 \mathrm{~ms})$, Fig. 14. These results are comparable with [20], and the greater time constant found for $25 \%$ BS solution could be attributed to the charge inhibiting effect of adsorbed proteinaceous materials, which hinders the charge transfer required for the repassivation process. Yan et al. [21] also suggested that the constituents of bovine serum can accelerate ion release and passive film breakdown. The gradual re-establishment of the electric double layer across the metal/electrolyte interface may also contribute to the slow recovery of current.

$I=I_{0}+A_{1} \exp \left(-\frac{t-t_{0}}{\tau}\right)$

where $I$ is the current generated during the indentation process, $I_{0}$ is the baseline current, $A_{1}$ is a current-related constant and $\tau$ is the time constant for repassivation.

The repassivation kinetics resulting from a single scratching test has been plotted in Fig. 15, which also follows a first-order exponential decay (Eq. 4). The repassivation takes a significantly longer time (around $1.5 \mathrm{~s}$ )
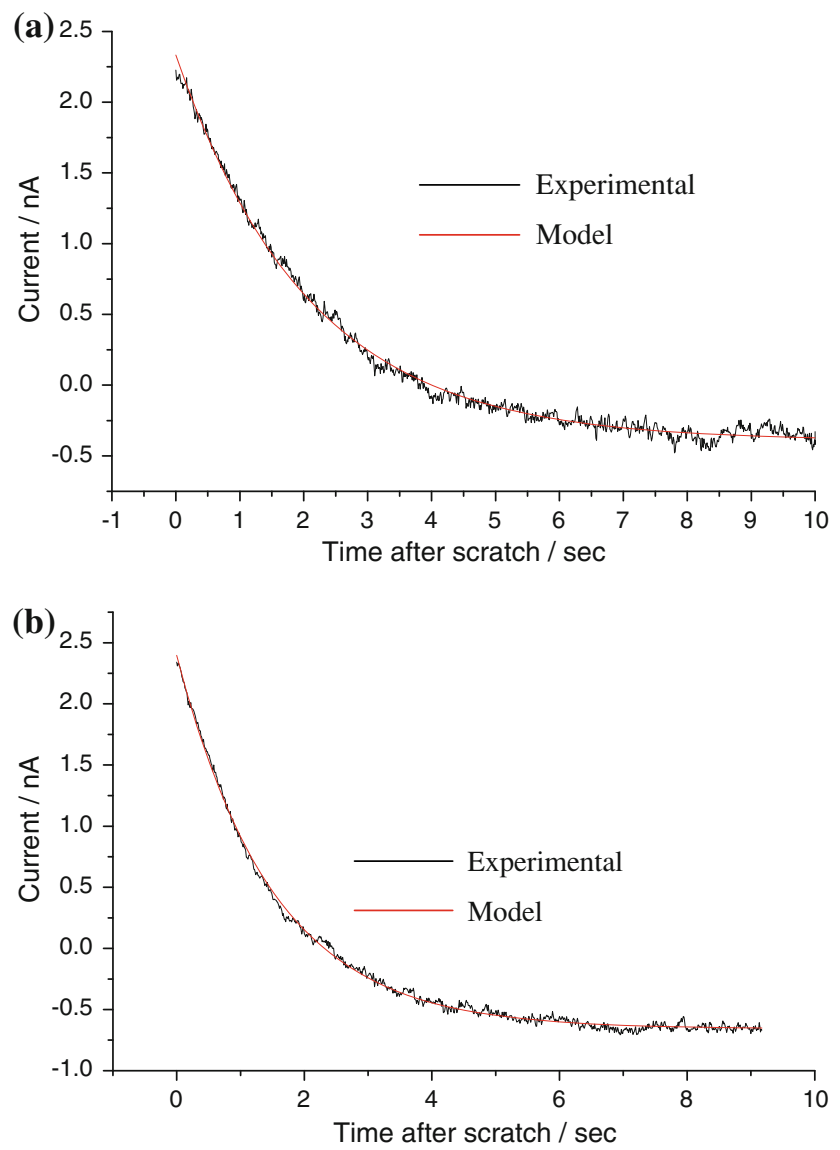

Fig. 15 Curve fitting for the repassivation process after a single scratch: a $0.9 \% \mathrm{NaCl}$ and b $25 \% \mathrm{BS}$

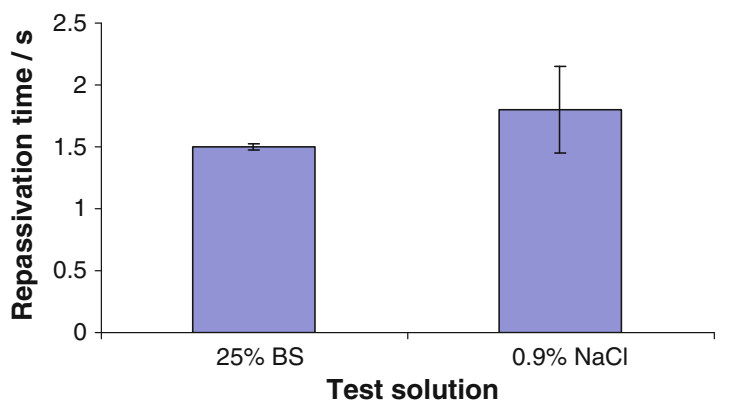

Fig. 16 Repassivation time for $0.9 \% \mathrm{NaCl}$ and $25 \% \mathrm{BS}$ in single scratch tests

compared to the wet-cell micro-indentation results for both test solutions; however, overall the single scratch repassivation times for the two test solutions are not significantly different, Fig. 16.

From the above analysis, it can be seen that the repassivation rate of the cast CoCrMo is very much dependent on the nature of the wear process, the extent of the surface oxide damage and the rate at which the surface damage is taking place. It has been estimated that the area of the damaged surface oxide resulted from single microindentation is about $6 \%$ and nano-scratching about $15-20 \%$ of the total worn area. These indicate that the oxide film formed on the CoCrMo is quite tenacious and will largely remain intact even under severe plastic deformation [22].

\section{Conclusions}

This article presents the micro- and nano-scale tribo-corrosion investigation of cast CoCrMo, the possible wearcorrosion mechanisms caused by a single entrained abrasive particle in CoCrMo hip joints have been elucidated. It has been found that the local plastic deformation caused by indentation or scratch could cause significant material microstructual changes and SIT. The actual affected surface area due to these tribological processes is greater than obvious indent or scratch areas due to extensive field of slip plane formation. The corrosion current patterns resulted from different tribological tests suggest that the major current flow (hence the major corrosion-induced material loss) is from the first indent and/or scratch made. The subsequent tribological processes mainly impose elastic deformation to the surface and only resulted in minor corrosion currents. The repassivation kinetics of cast CoCrMo after wet-cell microindentation and nanoscratching can be described by first-order exponential decay, and the experimental conditions have a strong impact over the repassivation/repassivation kinetics of the CoCrMo. 


\section{Appendix}

Equations for repaired film area calculation:

$$
\begin{array}{r}
Q=\int_{0}^{t}\left(I_{\mathrm{a}}-I_{0}\right) \mathrm{d}(t) \\
m_{\mathrm{Cr}}=\frac{Q M_{\mathrm{Cr}}}{F z} \\
m_{\mathrm{Cr}_{2} \mathrm{O}_{3}}=\frac{M_{\mathrm{Cr}_{2} \mathrm{O}_{3}}}{M_{\mathrm{Cr}}} m_{\mathrm{Cr}} \\
A_{\text {damage }}=\frac{m_{\mathrm{Cr}_{2} \mathrm{O}_{3}}}{\rho_{\mathrm{Cr}_{2} \mathrm{O}_{3}} h} \\
\text { repair\% }=\frac{A_{\text {damage }}}{A_{\text {total }}}
\end{array}
$$

where $Q$ is the total electric charge passed through the substance, $I_{\mathrm{a}}$ is the wear-induced corrosion current, $I_{0}$ is the corrosion current under statically immersed condition, $t$ is time, $m_{\mathrm{Cr}}$ is the mass of the corroding material (assuming Cr only), $F=96,485 \mathrm{C} \mathrm{mol}^{-1}$ is the Faraday constant, $z$ is the valence number of ions of the substance (electrons transferred per ion, in this case for $\mathrm{Cr}, z=3$ ), $M$ is the molar mass of the material, $A_{\text {damage }}$ is the area of film being damaged, $h$ is the thickness of the material and $A_{\text {total }}$ is the total indent area (total deformation area).

\section{References}

1. Wimmer, M.A., Loos, J., Nassutt, R., Heitkemper, M., Fischer, A.: The acting wear mechanisms on metal-on-metal hip joint bearings: in vitro results. Wear 250, 129-139 (2001)

2. Wimmer, M.A., Sprecher, C., Hauert, R., Tager, G., Fischer, A.: Tribochemical reaction on metal-on-metal hip joint bearings: a comparison between in vitro and in vivo results. Wear $\mathbf{2 5 5}$, 1007-1014 (2003)

3. Catelas, I., Bobyn, J.D., Medley, J.B., Krygier, J.J., Zukor, D.J., Petit, A., Huk, O.L.: Effects of digestion protocols on the isolation and characterization of metal-metal wear particles. I. Analysis of particle size and shape. J. Biomed. Mater. Res. 55(3), 320-329 (2001)

4. Wang, A., Bobyn, J.D., Yue, S., Medley, J.B., Chan, F.W.: Residual abrasive material from surface grinding of metal-metal hip implants: a source of third-body wear? In: Disegi, J.S., Dennedy, R.I., Pilliar, R.M. (eds.) ASTM Special Technical Publication 1365, pp. 125-134. American Society for Testing and Materials, Philadelphia (1999)

5. Howie, D.W., McCalden, R.W., Nawana, N.S., Costi, K., Pearcy, M.J., Subramanian, C.: The long-term wear of retrieved McKeeFarrar metal-on-metal total hip prostheses. J. Arthroplast. 20(3), 350-357 (2005)
6. Lippincott, A.L.I., Dowling, J.M., Medley, J.B., Christensen, R.W.: Temporomandibular joint arthroplasty using metal-onmetal and acrylic-on-metal configurations: wear in laboratory tests and in retrievals. Surg. Technol. Int. VIII, 321-330 (2000)

7. Reinisch, G., Judmann, K.P., Lhotka, C., Lintner, F., Zweymuller, K.A.: Retrieval study of uncemented metal-metal hip prostheses revised for early loosening. Biomaterials 24(6), 1081-1091 (2003)

8. Sun, D., Wharton, J.A., Wood, R.J.K.: Abrasive size and concentration effects on the tribo-corrosion of cast CoCrMo alloy in simulated body fluids. Tribol. Int. 42(11-12), 1595-1604 (2009)

9. Sun, D., Wharton, J.A., Wood, R.J.K.: Micro-abrasion-corrosion of cast $\mathrm{CoCrMo}$ - effects of micron and sub-micron sized abrasives. Wear 267(1-4), 52-60 (2009)

10. Sun, D., Wharton, J.A., Wood, R.J.K., Ma, L., Rainforth, W.M.: Microabrasion-corrosion of cast CoCrMo alloy in simulated body fluids. Tribol. Int. 42(1), 99-110 (2009)

11. Sun, D., Wharton, J.A., Wood, R.J.K.: Micro-abrasion mechanisms of cast CoCrMo in simulated body fluids. Wear 267(11), 1845-1855 (2009)

12. Sun, D., Wharton, J., Wood, R.: The effects of proteins and $\mathrm{pH}$ on tribo-corrosion performance of cast $\mathrm{CoCrMo}-\mathrm{a}$ combined electrochemical and tribological study. Tribol. Mater. Surf. Interface 2(3), 150-160 (2008)

13. Zhao, J.C.: Methods for Phase Diagram Determination. Elsevier Science, Amsterdam (2007)

14. Wu, X., Tao, N., Hong, Y., Liu, G., Xu, B., Lu, J., Lu, K.: Straininduced grain refinement of cobalt during surface mechanical attrition treatment. Acta. Mater. 53(3), 681-691 (2005)

15. Shetty, H.R., Kosel, T.H., Fiore, N.F.: A study of abrasive wear mechanisms in cobalt-base alloys. Wear 84(3), 327-343 (1983)

16. Richardson, T., Cottis, B., Lindsay, R., Lyon, S., Scantlebury, D., Stott, H., Graham, M. (eds.): Shreir's Corrosion. Elsevier Science, Amsterdam (2010)

17. Yamamoto, T., Fushimi, K., Seo, M., Tsuri, S., Adachi, T., Habazaki, H.: Current transient during repeated micro-indentation test of passive iron surface in $\mathrm{pH} 8.4$ borate buffer solution. Electrochem. Commun. 9, 1672-1676 (2007)

18. Igual Munoz, A., Mischler, S.: Interactive effects of albumin and phosphate ions on the corrosion of a CoCrMo implant alloy. J. Electrochem. Soc. 154(10), C562-C570 (2007)

19. Yan, Y., Neville, A., Dowson, D., Williams, S., Fisher, J.: Tribofilm formation in biotribocorrosion-does it regulate ion release in metal-on-metal artificial hip joints? Proc. Inst. Mech. Eng. J. 224(9), 997-1006 (2010)

20. Contu, F., Elsener, B., Assi, F., Bohini, H.: Repassivation behavior of metallic implants in inorganic and physiological electrolytes. In: Stallforth, H., Revell, P. (eds.) Materials for Medical Engineering, pp. 236-242. Wiley-VCH Verlag GmbH \& Co. KGaA, Weinheim, FRG (2005)

21. Yan, Y., Neville, A., Dowson, D.: Biotribocorrosion of CoCrMo orthopaedic implant materials-assessing the formation and effect of the biofilm. Tribol. Int. 40(10-12), 1492-1499 (2007)

22. Fushimi, K., Takase, K., Azumi, K., Seo, M.: Current transients of passive iron observed during micro-indentation in $\mathrm{pH} 84$ borate buffer solution. Electrochim. Acta 51(7), 1255-1263 (2006) 